
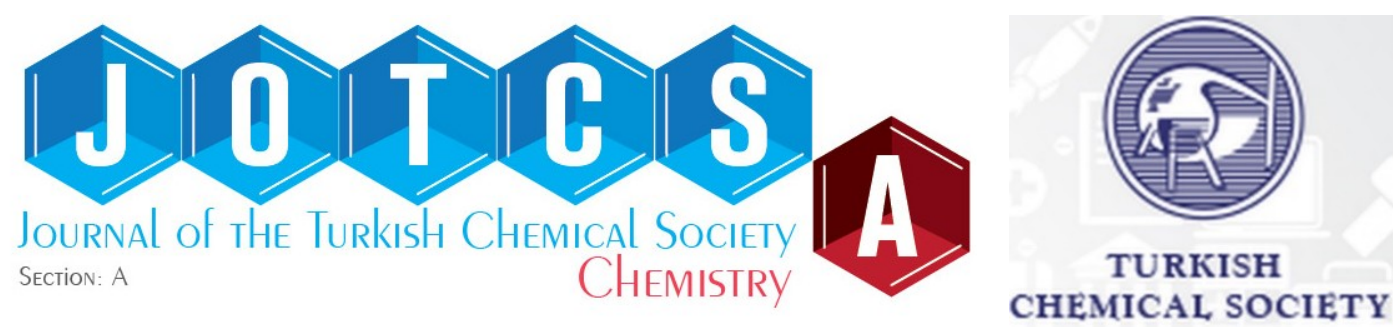

\title{
A Self-Healing Material Based on Microcapsules of Poly(Urea- Formaldehyde)/Bis-Propargyl-Succinate Containing in Polyurethane Matrix
}

\author{
Thi Sinh Vo'* $M$, Tran Thi Bich Chau Voª \\ Thi Ngoc Huyen Lai ${ }^{4}$
}

\begin{abstract}
${ }^{1}$ School of Mechanical Engineering, Sungkyunkwan University, Suwon 16419, Korea.
${ }^{2}$ Department of Industrial Management, Can Tho University, Can Tho, Vietnam.

${ }^{3}$ Department of Chemistry, Memorial University of Newfoundland, St. John's, NF A1B 3X7, Canada.

${ }^{4}$ School of Advance Materials Science \& Engineering, Sungkyunkwan University, Suwon 16419, Korea.
\end{abstract}

\begin{abstract}
With the development of current technology, several concepts of self-healing materials (SHMs) have recently been proposed, and capsule-based SHMs are explored. In our study, a terminal alkyne compound (bis-propargyl-succinate, BPS) is concerned as a healing agent to be used as a core material, and poly(urea-formaldehyde) (PUF) is employed as a wall shell. Besides, the chemical, morphological and thermal properties of the microcapsules (MCs) are also determined by Fouriertransform infrared spectroscopy (FTIR), gas chromatography (GC), thermogravimetric analysis (TGA), and optical microscopy (OM). Additionally, the MCs have better thermal stability up to $257^{\circ} \mathrm{C}$ with the rough outer surface. The MCs have successfully encapsulated $75.0 \%$ of BPS with a size range of $63-$ $125 \mu \mathrm{m}$ and PUF shell thickness range of $5.72-11.35 \mu \mathrm{m}$; moreover, the stability of MCs is well maintained within 50 days at room temperature basing on the solvent extraction method. Concomitantly, self-healing ability is activated by the breakup of the MCs as cracks, then the healing agent (BPS) is released into the cracked regions to react with azide groups of the polymeric matrix. The BPS in the MCs is moved to cracked regions, which involves MCs diameter and weight fraction of PUF capsules. Moreover, the self-healing ability can reach high when BPS amounts (i.e., SHMs containing $5 \%$ and $10 \%$ of MCs) are available sufficiently to be outrightly filled into the cracked regions. Thereby, MCs' size and weight fraction can be reasonably selected to result in an optimal healing capacity for a preestablished size of cracks.
\end{abstract}

Keywords: Microcapsules, healing agent, urea-formaldehyde, self-healing materials.

Submitted: May 08, 2021. Accepted: July 09, 2021.

Cite this: Vo TS, Vo TTBC, Pham ND, Lai TNH. A Self-Healing Material Based on Microcapsules of Poly(Urea-Formaldehyde)/Bis-Propargyl-Succinate Containing in Polyurethane Matrix. JOTCSA. $2021 ; 8(3): 787-802$.

DOI: https://doi.org/10.18596/jotcsa.934775.

*Corresponding author. E-mail: vtsinh92@skku.edu.

\section{INTRODUCTION}

Currently, several concepts of self-healing materials (SHMs) have recently been considered. At the same time, SHM is an artificial or synthetically-created material to be automatically repaired damages to themselves without any external diagnosis or human intervention. The SHMs can be classified primarily into different approaches basing on self-healing mechanisms (i.e., vascular, capsule-based, and intrinsic). The approaches also diversify by various damaged 
volumes to can heal, as well as the healing ability can be repeated in the same location and the rate of healing, leading to each approach having advantages and challenges to investigate. Moreover, microcapsule (MC)-based SHMs contain a healing agent that is capsuled and protected from different globular shells when the damages break them, at the same time that the self-healing mechanism is based on releasing the healing agent in the MCs to react with the polymeric matrix at the damaged region. The polymer shell walls are created from a number of techniques to protect the core materials (healing agents) containing inside them; in particular, the most common methods relate to the shell formation at the interface of droplets in an oil-in-water emulsion (1). Additionally, the damages and cracks regularly appear on/in the polymeric materials during a used long-term, which loses their necessary functions and impacts to their mechanical properties (2-5). The fabrication methods of SHMs are concerned as a significant role in maintaining the necessary properties of materials; thus, the source materials have a self-healing ability in the damaged polymeric matrix is considered as a healing agent that is truly attracted to can investigate its abilities $(3-6)$.

Simultaneously, polyurethane (PU) is one of synthetic polymers, that is formed from a polycondensation reaction of a terminal hydroxyl group-contained pre-polymer and a di-isocyanate (or a polyisocyanate) (7-9). A typical classification utilized for powerful and selective reactions is mentioned to a "azide-alkyne" click reaction that is conducted by compounds containing azide and alkyne groups (10-13). Here, a terminal alkyne ($\mathrm{C} \equiv \mathrm{C}-$ ) compound can be well prepared through one-step method with a suitable molar ratio of reactants as shown in our previous works $(13,14)$, while glycidyl azide polyol (GAP, a pre-polymer) is known an azide $\left(-\mathrm{N}_{3}\right)$ compound containing terminal hydroxyl $(-\mathrm{OH})$ group that can well react with isocyanate $(-\mathrm{N}=\mathrm{C}=\mathrm{O})$ compound to form an azide group-contained PU matrix (13, 14). Remarkably, the preliminary healing ability on the SHMs has been investigated in the first study of ours (13), which was based on the direct injection method by the various assuming cuts on the GAPbased PUs, the as-prepared bis-propargylsuccinate (BPS) was then injected to repair the damaged regions (assuming cuts) of the GAPbased PUs. Thus, this is a precondition to continue conducting an investigation of PU/MCs-based SHMs in this study, as well as which can be a novel SHMs on the basic of "azide-alkyne" click reaction between an azide group-contained polymeric matrix (the as-prepared GAP-based PU) and a terminal alkyne compound-contained healing agent (the as-prepared BPS). Specifically, it uses only one type of healing agent (alkyne compound)contained capsule instead of two different healing agents (azide and alkyne compounds)-contained capsules on a polymeric matrix (polyisobutylene) by Gragert et al. (15), or one healing agent (the azide compound)-contained capsule on a polymeric matrix (alkyne-graphene oxide) with the use of copper-catalyzed azide-alkyne (CuAAC) click reaction by Akhan et al. (16). As limitation of the use of CuAAc regrading to diffusion of the participating reactants, Dohler et al. (17) performed more extensively in variety of multivalent azide/alkyne compounds and polymers grafted with various molecular weights, viscosities, and functional group densities. Further, Saikia et al. (18) also designed an azide-alkyne cycloaddition-based SHMs through azide-multiwall carbon nanotubes with poly(t-butyl acrylate) and alkyne compound-contained capsule embedded in an epoxy matrix. On the basic of any damaging event occurs in the epoxy matrix, the healing liquid could dissolve the implanted catalyst from the matrix to occur the crosslinking reaction between azide and alkyne leading to healing the cracks, as well as investigated the influences of temperature and healing time (18).

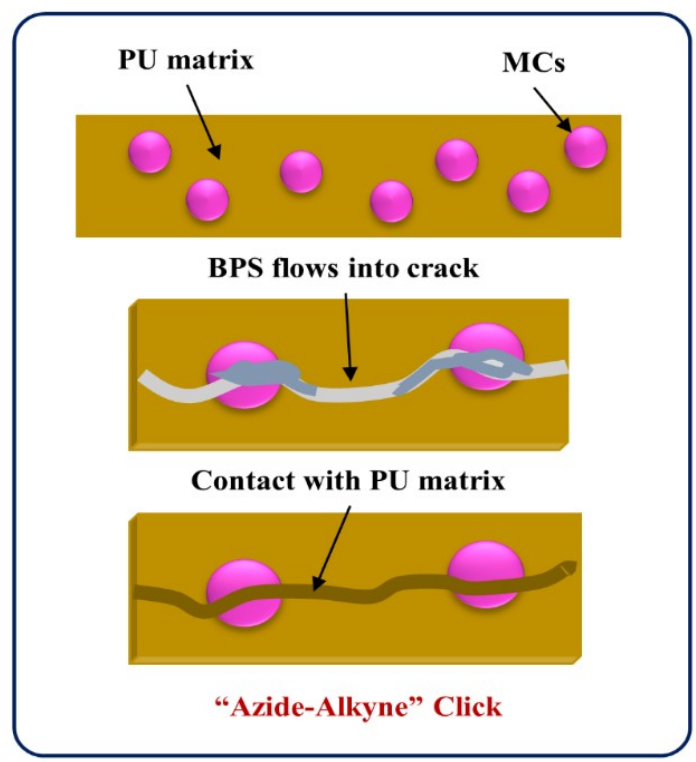

Figure 1: Self-healing mechanism of PU/MCsbased SHMs using "azide-alkyne" click.

Thereby, a terminal alkyne compound BPS is concerned as a healing agent to be used as a core material, and poly(urea-formaldehyde) (PUF) is employed as a wall shell. BPS was prepared through an esterification reaction in our previous works $(13,14)$, while PUF/BPS MCs are fabricated in an oil-in-water emulsion to conduct surveys of chemical, morphological, and thermal properties of the as-prepared MCs based on Fourier-transform infrared spectroscopy (FTIR), gas chromatography 
(GC), thermogravimetric analysis (TGA), and optical microscopy (OM). Concomitantly, the stability of the as-prepared MCs is also investigated at room temperature following a storage time cycle by the solvent extraction method. Moreover, the self-healing ability of SHMs is activated by the breakup of the above MCs as cracks, an amount of healing agent liquid (BPS) in the MCs is released to move into the cracked regions, conducting a reaction of "azide-alkyne" click [i.e., azide groups of the polymeric matrix (GAP-based PU) and alkyne groups of healing agent (BPS)] $(12,19,20)$ (Figure 1). Besides, the influences of MCs content, diameter, and crack types on PU/MCs-based SHMs are also investigated. These can open a new approach for the fabrication of capsule-based SHMs from GAPbased PU matrices.

\section{MATERIALS AND METHODS}

\section{Materials}

GAP polyols were offered from the Korean Company. Poly(ethylene-alt-maleic anhydride) $\left(E M A, M_{w}=100,000-500,000\right)$ was provided from Sigma company. Ammonium chloride $98+\%$ was obtained from the Alfa Aesar company. Resorcinol $98.0 \%$ and Urea $99.0 \%$ were purchased from Samchun Company. Formaldehyde solution $37.0 \%$ were offered from Junsei Chemical Co., Ltd (Japan). BPS was synthesized via an esterification reaction in our previous work to be continued using as a core material in this study (13).

\section{Fabrication of PUF/BPS MCs}

MCs are fabricated in an oil-in-water emulsion by the in-situ polymerization method. $2.50 \mathrm{~g}$ of urea, $0.25 \mathrm{~g}$ of ammonium chloride, and $0.25 \mathrm{~g}$ of resorcinol are added and stirred into EMA aqueous solution $(0.5 \mathrm{wt} \%)$ at $55{ }^{\circ} \mathrm{C}$. The $\mathrm{pH}$ solution is adjusted (i.e., $\mathrm{pH}=2.60-3.50$ ) by hydrochloric acid $(\mathrm{HCl})$ and sodium hydroxide $(\mathrm{NaOH})$. Especially, 1-octanol is supplemented into the above solution to avoid surface bubbles. The BPS is added slowly to obtain an emulsion and stabilized for $10 \mathrm{~min}$. Thereafter, the formaldehyde solution is added to achieve a $1 / 1.9$ molar ratio of formaldehyde/urea. After $4 \mathrm{~h}$, the suspension of MCs is separated, as based on filter papers under vacuum. Finally, the MCs are washed with a solvent mixture (distilled water: n-hexane), which then are air-dried for $24-48 \mathrm{~h}$. Herein, sieves (Chung Gye Sang Gong SA) are employed to separate the sizes of the MCs.

\section{Preparation of PU/MCs-based SHMs}

GAP polyol $(8.00 \mathrm{~g})$ is dried at $60^{\circ} \mathrm{C}$ under vacuum and cooled down to $25^{\circ} \mathrm{C}-30^{\circ} \mathrm{C}$. Then, IPDI $(0.45 \mathrm{~g})$ is quickly added and stirred in the GAP polyol $\left(25-30^{\circ} \mathrm{C}\right)$. Next, $0.15 \mathrm{~g}$ of TPB solution (20 $\mathrm{wt} \%$ in BZ), $0.24 \mathrm{~g}$ of DNS solution (12.5 wt\% in BZ), and $0.44 \mathrm{~g}$ of MCs ( $5 \mathrm{wt} \%$ of PU) are added and stirred under vacuum. Finally, the above mixture is filled into a mold $(3 \mathrm{~cm} \times 8$ $\mathrm{cm}$ ) to continue removing the bubbles under vacuum $\left(30{ }^{\circ} \mathrm{C}, 3 \mathrm{~h}\right)$; the curing process of PU/MCs-based SHMs is conducted in the oven (60 ${ }^{\circ} \mathrm{C}, 7$ days) $(13,14)$. The reaction scheme of $\mathrm{PU} / \mathrm{MCs}$-based SHMs is described in Figure 2.

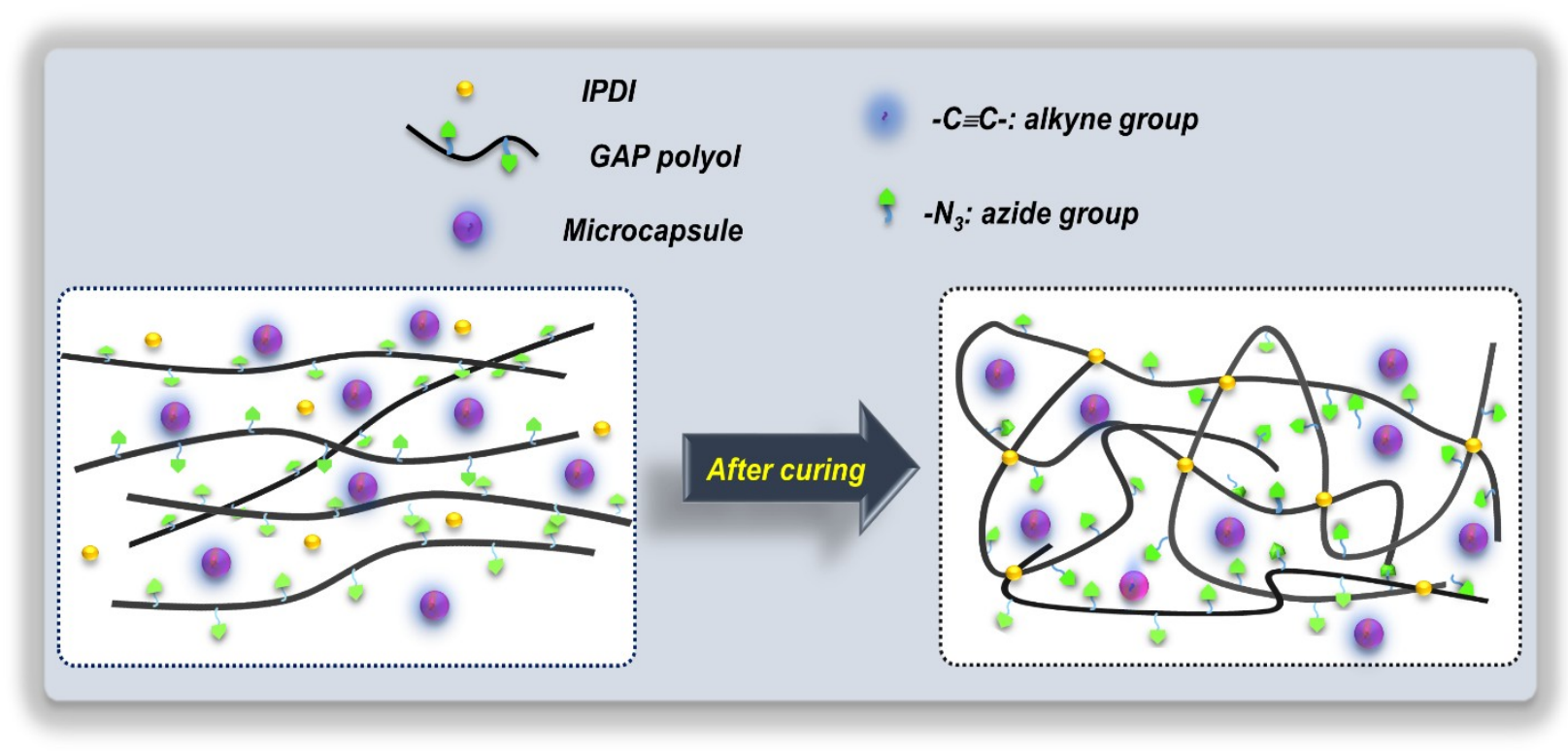

Figure 2: Formation scheme of PU/MCs-based SHMs.

Instruments of analysis
Fourier-transform infrared spectroscopy (FT-IR) of the samples is scanned in the $4000-400 \mathrm{~cm}^{-1}$ 
region (Nicolet 380, Ietled Co.). Thermogravimetric (TGA) curves of the samples are conducted from 50 to $850{ }^{\circ} \mathrm{C}$ with a ramp rate of $20^{\circ} \mathrm{C} \mathrm{min}-1$ under the dry nitrogen atmosphere (20 mL/min) by a Seiko Exstar6000 (TGA4000, PerkinElmer). Surface morphology of the asprepared MCs is performed with an optical microscope (OM) (Olympus SZX12) and iSolution $^{\text {TM }}$ IMTcamCCD Digital Camera. The diameter of the as-prepared MCs is determined from Standard Testing Sieves (Chung Gye Sang Gong SA). A gas chromatograph (GC) (Shimadzu, Inc.) with a $320 \mu \mathrm{m}$ internal diameter capillary column and flame ionization detector is employed to determine the core materials in MCs. The GC samples are prepared by adding MCs into a vial containing acetone, which is then filtered and collected the liquid to measure.

\section{RESULTS AND DISCUSSION}

\section{Morphological characterization of PUF/BPS MCs}

A chemical method with in-situ polymerization has been applied for the fabrication of MCs (1). In this process, the polymerization is conducted in/on the continuous phase of the interface through the dispersed core material. Initially, a polymer with low molecular weight (i.e., prepolymer) will be formed; as time goes on, it grows in size. It means that this polymer will deposit on the surface of the dispersed core material, thereby generating a solid capsule shell. In the fabrication process of the MCs, the PUF/BPS MCs have been rinsed with distilled water: n-hexane, which then are air-dried at room temperature-resulting from that the yield of spherical MCs was obtained to $82.0 \%$ after airdried 2 days. Besides, the formation of poly(ureaformaldehyde) (PUF) capsules has been included a possible reaction of urea and formaldehyde to attain methylol urea and dimethylol urea (Figure 3) during in-situ polymerization, which continues a condensation under acidic conditions to collect the PUF wall shell in Figure 4. Herein, BPS is concerned as a healing agent to be encapsulated in PUF capsules.

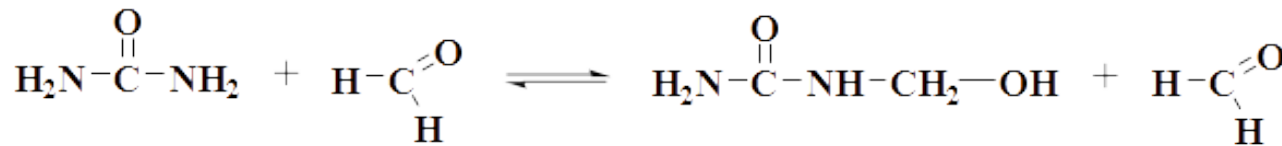

$$
\begin{aligned}
& \text { Urea Formaldehyde } \\
& \text { Methylol urea }
\end{aligned}
$$

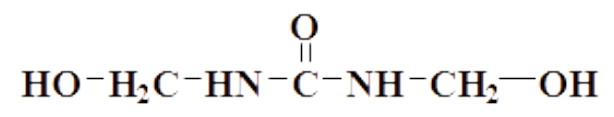

\section{Dimethylol urea}

Figure 3: Formation scheme of methylol urea and dimethylol urea.

Furthermore, the encapsulation of BPS in the PUF capsules takes place simultaneously during the formation of crosslinked PUF. Urea and formaldehyde are all soluble in an aqueous medium, which can react to each other to form PUF as mentioned above in an acidic environment and $55^{\circ} \mathrm{C}$. During the initial stage of the in-situ polymerization, the urea-formaldehyde molecule is rich with polar groups (i.e., methylol urea, dimethylol urea, or low molecular weight compound) is compatible with water. Besides, the number of polar groups will gradually decrease with an increase in polymer molecular weight, which reduced the hydrophilicity of PUF molecules to separate from the aqueous phase and deposited on the already emulsified oil droplets (i.e., hydrophobic organic phase) after this molecular weight attained a certain value. The PUF shell thickness has been optimized in order that this PUF shell contains the maximum amount of core material. Here, the diameter of the prepared PUF/BPS MCs is separated from standard testing sieves. Four standard testing sieves with different mesh sizes $(180,150,125$, and $63 \mu \mathrm{m})$ were used to separate the particles. The PUF/BPS MCs size range of $63-125 \mu \mathrm{m}$ (Figure 5 ) is chosen to apply for the preparation process of SHMs. 


\section{POLY UREA FORMALDEHYDE \\ NETWORK TYPE I}
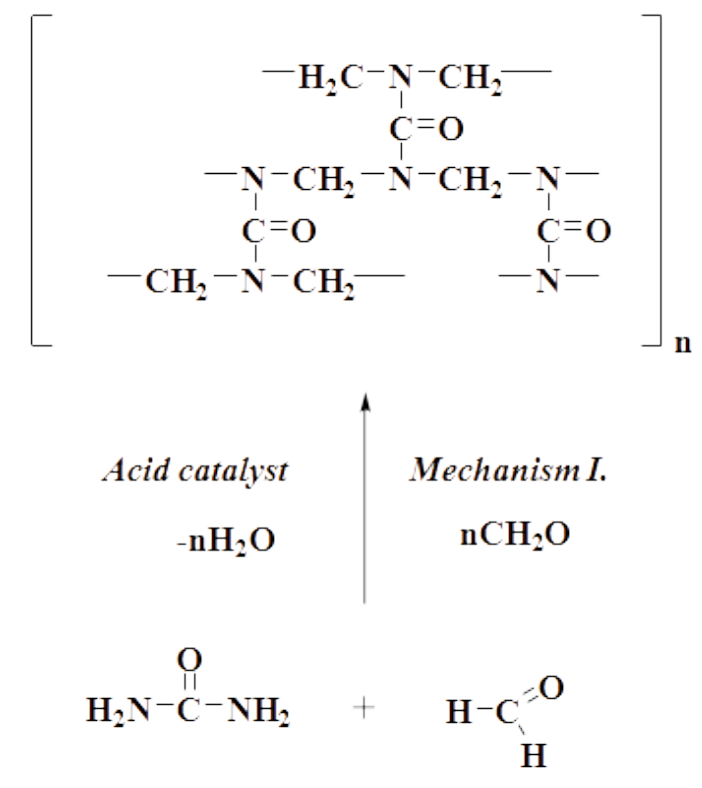

UREA

FORMALDEHYDE

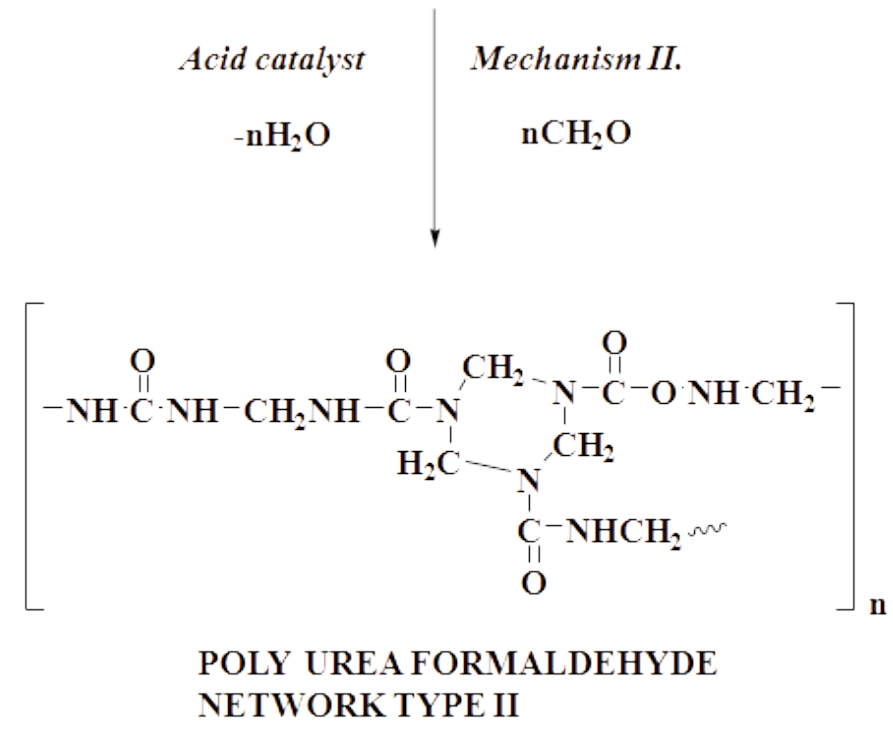

Figure 4: Possible formation of PUF during in-situ polymerization.

In Figure 5, it shows the OM micrographs of MCs morphology. Overall, the microencapsulation efficiency of the prepared PUF/BPS MCs has occurred condensation reaction for the PUF wall shell; its strength cannot endure the treatment such as washing and separation (Standard testing sieves) because PUF particles have been moved out the capsules. At the same time, most of the prepared PUF/BPS MCs are round globules; the PUF particles will deposit much around the capsules leading to the outer surface of the MCs becoming rougher, as well as the MCs are tightly clustered together. Furthermore, the PUF particles deposit around the capsules and separate out the capsules, indicating that the inner surface of the capsule is smoother than the outer surface of the capsule. In other words, the polymeric membrane is formed to be protected the MCs well. Additionally, the less thickness MCs did not rupture after they were separated via standard testing sieves. 

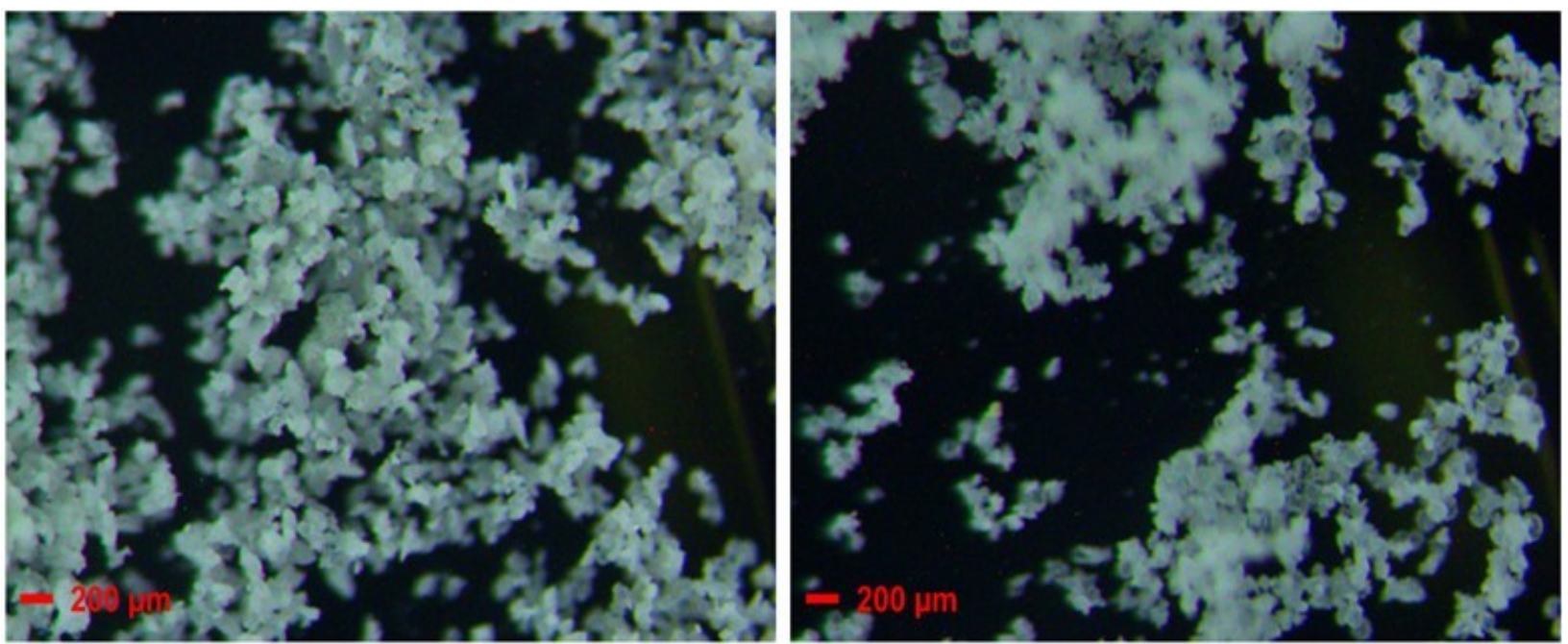

Figure 5: OM micrographs of PUF/BPS MCs.

\section{Encapsulation ability of BPS into the PUF} capsules

MCs are prepared from the PUF shell and the filled BPS to be characterized through different instrumental techniques. In particular, chemical characterization of the as-prepared MCs is investigated by FTIR spectroscopy, as shown in Figure 6. For PUF spectra (Figure 6A), peaks of O$\mathrm{H}$ and $\mathrm{N}-\mathrm{H}$ stretching vibrations are assigned at $3390 \mathrm{~cm}^{-1}$, and a peak at $2969 \mathrm{~cm}^{-1}$ is the stretching vibration of saturated $\mathrm{H}-\mathrm{C}-\mathrm{H}$ symmetry and inverse symmetry. Besides, the peaks at 1652 $\mathrm{cm}^{-1}, 1560 \mathrm{~cm}^{-1}$, and $1251 \mathrm{~cm}^{-1}$ belong to $\mathrm{NH}-$ CO-NH, N-H, and C-O-C stretching vibrations, respectively. A peak of $\mathrm{C}-\mathrm{H}$ bending vibration is observed at $1382 \mathrm{~cm}^{-1}$; C-N stretching vibrations are assigned at $1194 \mathrm{~cm}^{-1}$ and $1116 \mathrm{~cm}^{-1}$. These results confirm that the shell material is successfully created from PUF wall shell basing on in-situ polymerization. Furthermore, in BPS spectra (Fig, 6B), C-H stretching and bending vibrations are observed at 2946 and $1417 \mathrm{~cm}^{-1}$, respectively. Peaks of $\mathrm{C}-\mathrm{O}$ stretching vibration are assigned at $1309 \mathrm{~cm}^{-1}$ and $1147 \mathrm{~cm}^{-1}$. Besides, special $\mathrm{H}-\mathrm{C} \equiv \mathrm{C}$ and $\mathrm{C} \equiv \mathrm{C}$ stretching vibrations in BPS are absorbed in $3257 \mathrm{~cm}^{-1}$ and $2133 \mathrm{~cm}^{-1}$, respectively. Peaks at $1724 \mathrm{~cm}^{-1}, 960 \mathrm{~cm}^{-1}$, and $798 \mathrm{~cm}^{-1}$ belong to $\mathrm{C}=\mathrm{O}$ stretching vibration, $\equiv \mathrm{C}-\mathrm{H}$ bending vibration, and $-\left(\mathrm{CH}_{2}\right)_{2}-$ unit stretching vibration. Overall, there is a matching of core material (BPS) and shell material (PUF) in PUF/BPS MCs spectra (Figure 6B), as well as the spectra of BPS and the core material inside the MCs, have also been confirmed a matching at above-mentioned characteristic peaks. Hence, it manifests that BPScore material has been successfully encapsulated in the PUF capsules.
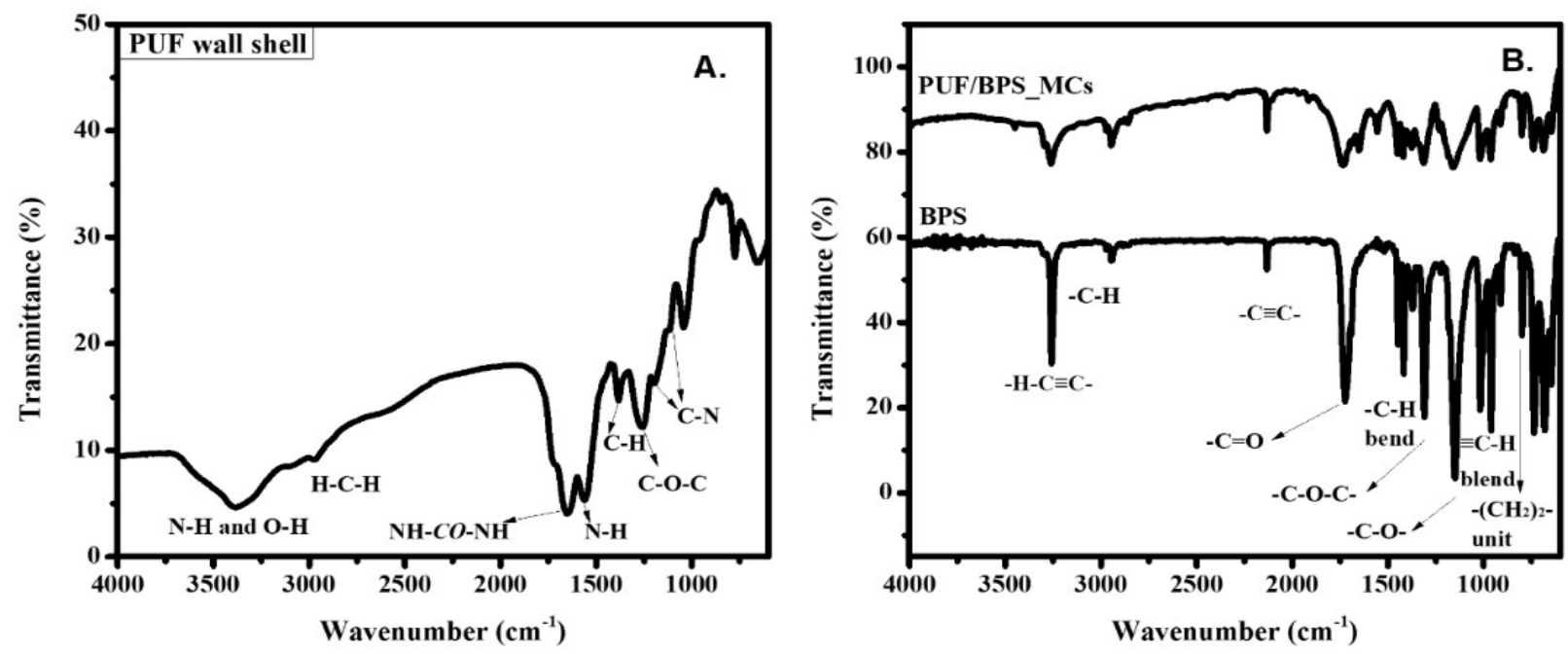

Figure 6: FT-IR spectra of PUF wall shell (A), PUF/BPS MCs, and BPS (B). 
To further evaluate MCs' characterization and the storage ability of BPS in the MCs, a gas chromatograph is applied to estimate the appearance of core material successfully encapsulated in the shell material. Here, the mixture of acetone and MCs are sealed to recognize the presence of BPS into the MCs for one week, as well as the core material has enough time to diffuse from the PUF capsules into the solvent. $\mathrm{GC}$ instrument is employed for the filtered solution

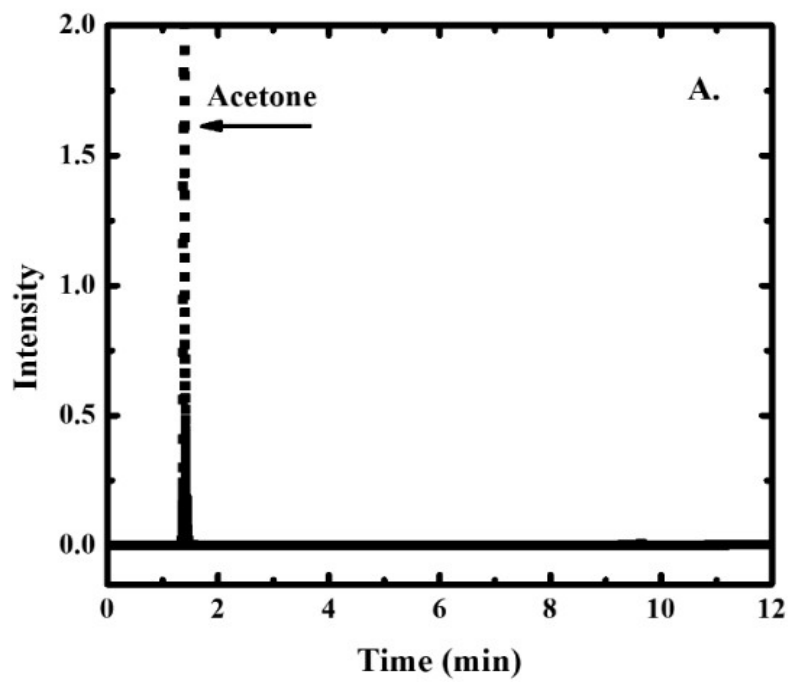

to can assess the presence of core material. From the $\mathrm{GC}$ results of this filtered solution, there is the only peak of acetone solvent, indicating that the core material is still kept in shell material during 5 days (Figure 7A); however, two peaks of core material (BPS) have appeared in this filtered solution after one week (Figure 7B). This result is also similar to the above FTIR report for successfully encapsulated BPS in UF shell material and the storage ability of BPS in the MCs.

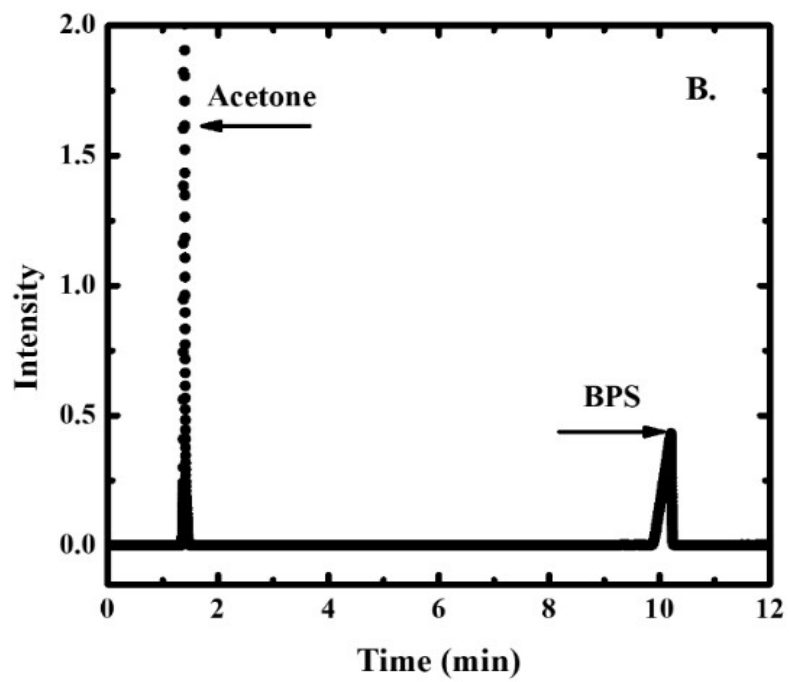

Figure 7: GC curves of a (Acetone: MCs) mixture after 5 days (A) and 7 days (B).

Content of BPS and PUF shell thickness in PUF/BPS MCs

The identification of BPS content in MCs is concerned as a major factor. In order to determine the content of BPS in the prepared MCs, five mixtures of PUF/BPS have been prepared as follows: $100 / 0,30 / 70,20 / 80,10 / 90$, and 0/100 (\%, wt/wt), which are then measured by TGA instrument as shown in Figure $8(A, B)$. The calibration curve for BPS content versus weight loss of BPS will be constructed (Figure $8 \mathrm{C}$ ) from the above-prepared mixtures, so the relationships of the content of BPS and the weight loss of BPS is calculated as shown in Equation 1, where $\mathrm{y}$ is the content of BPS, and $x$ is the weight loss of BPS from the TGA curve. Based on Equation 1, the content of BPS in the prepared MCs can be identified, resulting in that the content of BPS in the prepared MCs achieved $75.0 \%$ [As shown in Figure 10, the obtained weight loss of BPS (WL = $\sim 77.0 \%$, at $210^{\circ} \mathrm{C}$ ) on the TGA curve of PUF/BPS MCs is considered as $x$-value that can be added in Eq. (1) to calculate the content of BPS ( $y$-value)]. At the same time, this method can be seen as a new one to identify the core material content in the MCs.

$$
y=0.1781 x^{2}+0.8300 x+0.0001
$$



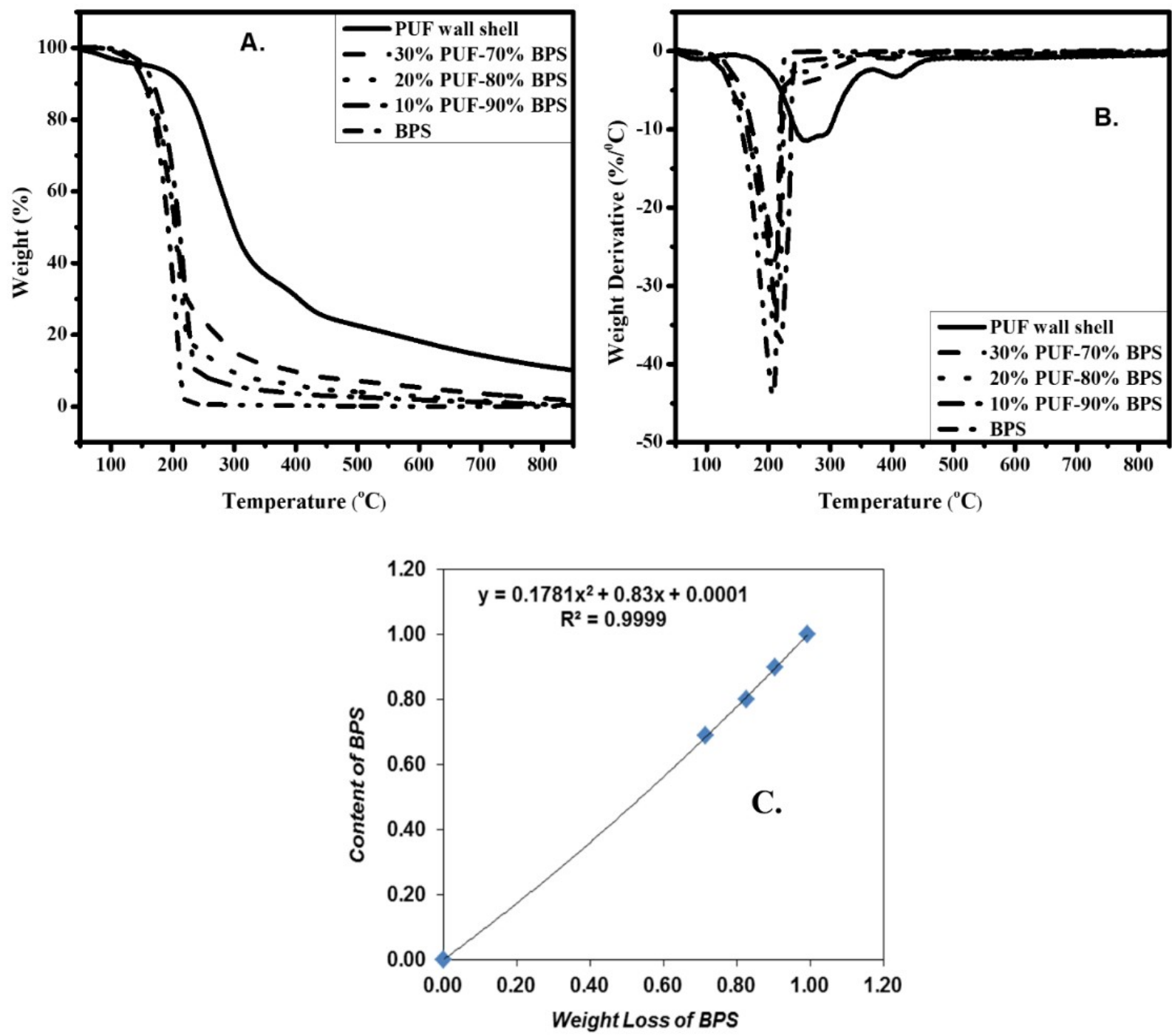

Figure 8: TGA (A) and DTG (B) curves of five mixtures. Calibration curve for content of BPS versus weight loss of BPS (C).

In addition to the above-mentioned identification method of the content of the core material, the content of BPS in the prepared MCs can also be determined by the solvent extraction method. The PUF/BPS MCs are crushed in a mortar with pestle. A solvent mixture (ethanol and acetone) is employed to dissolve and extract the core material from these MCs. Next, the insoluble PUF shell is filtered, washed, and dried for 12 - $24 \mathrm{~h}$. The content of encapsulated core material $\left(E_{c}\right)$ in the prepared MCs is calculated by Equation $2 ; \mathrm{W}_{\mathrm{s}}$ and
$\mathrm{W}_{\mathrm{i}}$ are the weight of the sample and the insoluble shell's weight, respectively. As a result, the content of BPS in the PUF/BPS MCs has been attained to $73.0 \%$. As such, the calculated contents of core material are similar in the two methods as mentioned above.

$$
E_{c}=\frac{\left(W_{S}-W_{i}\right)}{W_{S}} \cdot 100 \%
$$




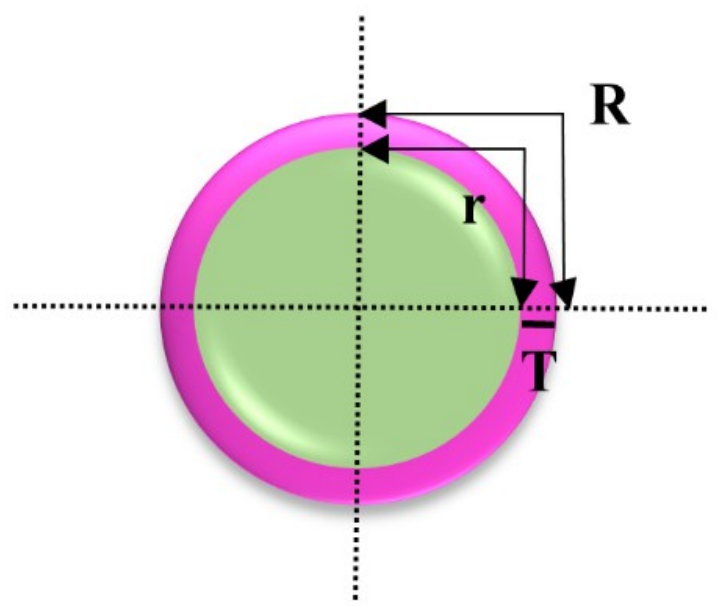

Figure 9: Schematic diagram of PUF/BPS MCs.

Additionally, the determination of the PUF shell thickness in PUF/BPS MCs is truly significant. The $\mathrm{MC}$ is supposed as a round globule (Figure 9) to calculate this PUF shell thickness in this study. The mass of PUF shell is shown in Equation $3, M_{s}$ is considered as the mass of PUF shell; $R$ and $r$ are seen with an order to as the MCs radius and the core of the MCs radius, and $\rho$ s is defined as the PUF density $\left(1.180 \mathrm{~g} / \mathrm{cm}^{3}(21,22)\right)$. Besides, the mass of BPS is shown in Equation $4, M_{C}$ is the mass of BPS, and $\rho c$ is the density of BPS (1.17 $\left.\mathrm{g} / \mathrm{cm}^{3}\right)$. The content of BPS (P) and the thickness of PUF shell ( $T$ ) are presented with an order in Equations 5 and 6 . Hence, from Equations 3 to 6 , it is truly easy to obtain the thickness of the PUF shell (Equation 7).

$$
\begin{aligned}
& \frac{4}{3} \cdot \pi \cdot \mathrm{R}^{3} \cdot \rho_{\mathrm{S}}-\frac{4}{3} \cdot \pi \cdot \mathrm{r}^{3} \cdot \rho_{\mathrm{s}}=\mathrm{M}_{\mathrm{S}} \\
& \frac{4}{3} \cdot \pi \cdot \mathrm{r}^{3} \cdot \rho_{\mathrm{C}}=\mathrm{M}_{\mathrm{C}} \\
& \mathrm{P}=\frac{\mathrm{M}_{\mathrm{C}}}{\mathrm{M}_{\mathrm{C}}+\mathrm{M}_{\mathrm{S}}} \cdot 100 \%
\end{aligned}
$$

$$
\begin{aligned}
& \mathrm{T}=\mathrm{R}-\mathrm{r} \\
& \mathrm{T}=\mathrm{R} \cdot\left(1-\frac{\sqrt[3]{\rho_{\mathrm{S}} \cdot \mathrm{P}}}{\rho_{\mathrm{C}}-\rho_{\mathrm{C}} \cdot \mathrm{P}+\rho_{\mathrm{S}} \cdot \mathrm{P}}\right)
\end{aligned}
$$

Based on the above Equation 7, the thicknesses of PUF shell are identified to be $5.72-11.35 \mu \mathrm{m}$ according to $63-125 \mu \mathrm{m}$ of diameters of MCs and $75.0 \%$ of MCs BPS content; concomitantly, the MCs fill percentage is estimated to be $76.0 \%$ by volume.

\section{Thermal properties of PUF/BPS MCs}

In addition to identifying the BPS content in the PUF/BPS MCs based on a TGA instrument, this instrument is also employed in an investigation of the thermal property of the PUF/BPS MCs, as well as the thermal stability of the MCs is considered as a significant factor in the practical application (23$25)$, the thermal analysis of the prepared MCs involve to both the PUF shell and BPS (core agent) to be conducted for the further characterization. Specifically, Figure 10 (A, B) displays TGA and DTG curves of PUF wall shell, PUF/BPS MCs, and BPS. In TGA and DTG curves of PUF wall shell, it shows that a little weight loss at $\sim 100{ }^{\circ} \mathrm{C}$ is primarily attributed to the elimination of free formaldehyde and an entrapped residual water (3, 26-30); in particular, the weight loss at $249{ }^{\circ} \mathrm{C}$ and $355^{\circ} \mathrm{C}$ are primarily ascribed to the PUF's decomposition. The residual undergoes extensive fragmentation above $500{ }^{\circ} \mathrm{C}$ (26-30). Additionally, the thermal degradation of MCs containing BPS is further much complexed than that of PUF shell material. The asprepared MCs are better thermal stability through the weight loss at $257{ }^{\circ} \mathrm{C}$ and $418{ }^{\circ} \mathrm{C}$, while the core material (BPS) degradation is initiated at 210 ${ }^{\circ} \mathrm{C}$ as shown in TGA and DTG curves. Hence, it is further confirmed that the as-prepared MCs truly contain both PUF (shell material) and BPS (core material), which is suitable with the above FTIR and $\mathrm{GC}$ reports. 

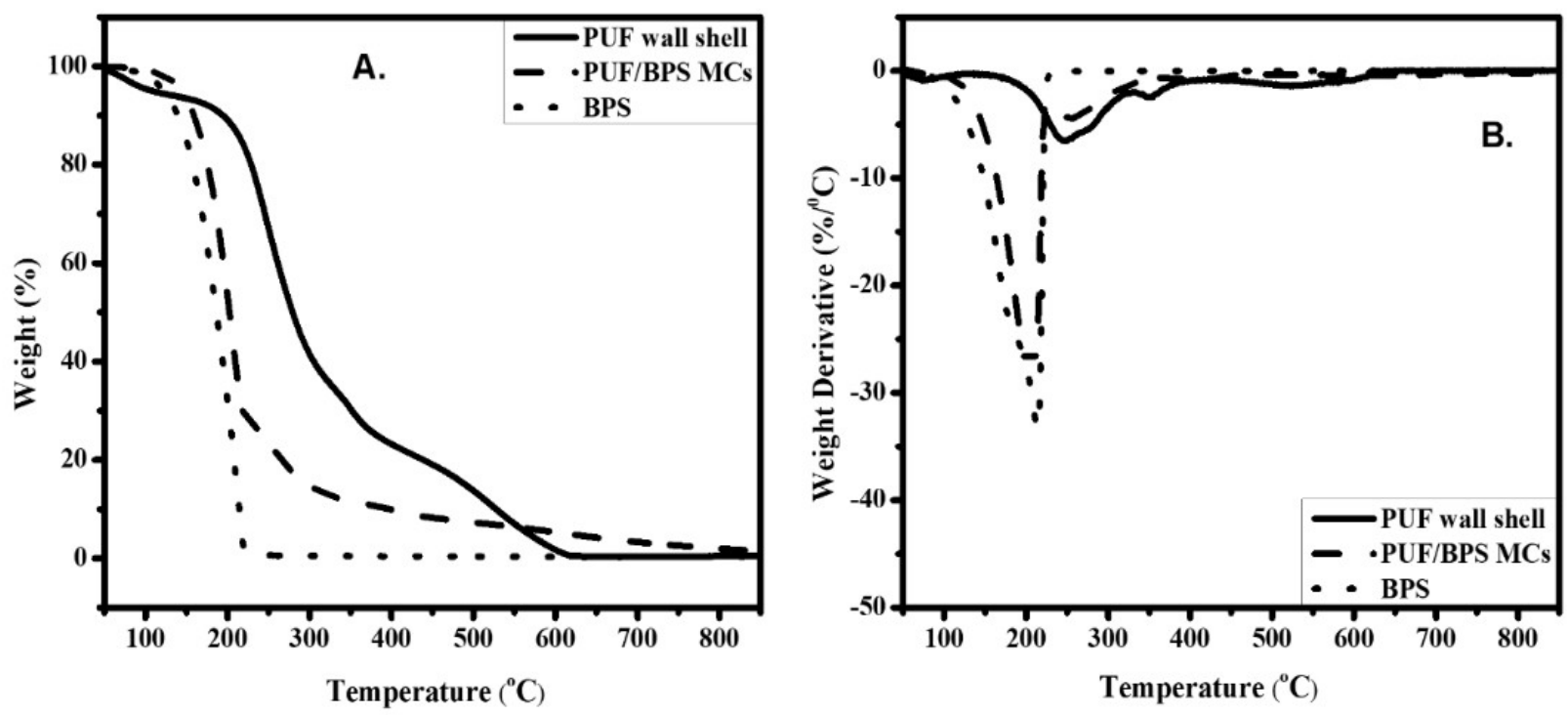

Figure 10: TGA (A) and DTG (B) curves of PUF wall shell, PUF/BPS MCs and BPS.

\section{Stability of PUF/BPS MCs}

In the practical application of the MCs, the storage ability (or stability) is seen as a significant factor; therefore, the stability of PUF/BPS MCs in this study is truly necessary to be investigated. Herein, the PUF/BPS MCs are crushed in a mortar and pestle mentioned in the solvent extraction method. A solvent mixture (ethanol and acetone) is employed to dissolve and extract the core material from these MCs. Next, the insoluble PUF shell is filtered, washed meticulously, and dried for 12 $24 \mathrm{~h}$. The core content in the MCs at the initial time and at storage time is calculated by Equation 2 , then the weight loss of MCs in the storage time is calculated by Equation $8, E_{c 1}$ and $E_{c 2}$ are initial content of core material and content of core material during the storage time, respectively.

$$
\mathrm{WL}=\frac{\mathrm{E}_{\mathrm{c} 1}-\mathrm{E}_{\mathrm{c} 2}}{\mathrm{E}_{\mathrm{c} 1}} \cdot 100 \%
$$

As shown in Figure 11, it indicates that the stability of MCs is well maintained within 50 days at room temperature, the weight loss of the MCs is about 0.20 wt $\%$ within 50 days, as well as the significant role of PUF shell in BPS protection. The weight loss of the PUF/BPS MCs becomes higher with the increasing tested storage time. At the same time, the weight loss of MCs in the storage time involves the diffusion of the core material over the PUF shell and the elimination of free-formaldehyde $(22,23)$ primarily. As such, this study can open an approach for preparing the PUF/BPS MCs are employed as healing agents.

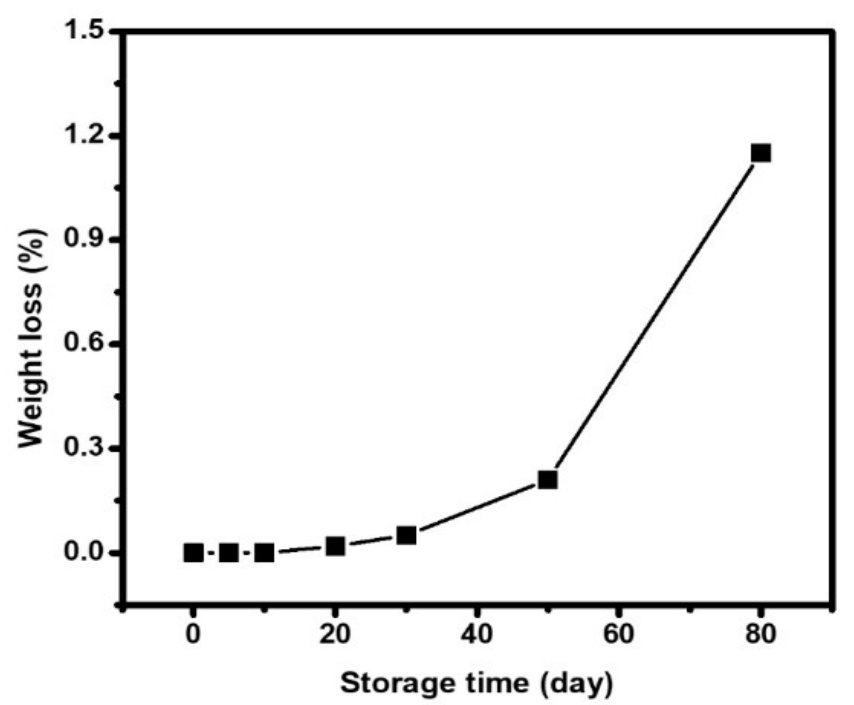

Figure 11: Weight loss of PUF/BPS MCs at room temperature. 


\section{Self-healing ability of PU/MCs-based SHMs}

As known, a healing agent is encapsulated and protected in globular capsules when damages break them. The self-healing mechanism is performed by releasing the healing agent to react with the polymeric matrix at the damage region. In particular, MC is seen as one of many applications of polymer to protect specific functional materials from or to release them into an outer phase for a long time. Herein, the self-healing ability of the PU/MCs-based SHMs is activated by rupture of the MCs in response to cracks, then an amount of BPS liquid in the MCs is released to move into the cracked regions, conducting reaction with the azide groups of the polymeric matrix (GAP-based PU) via "azide-alkyne" click.
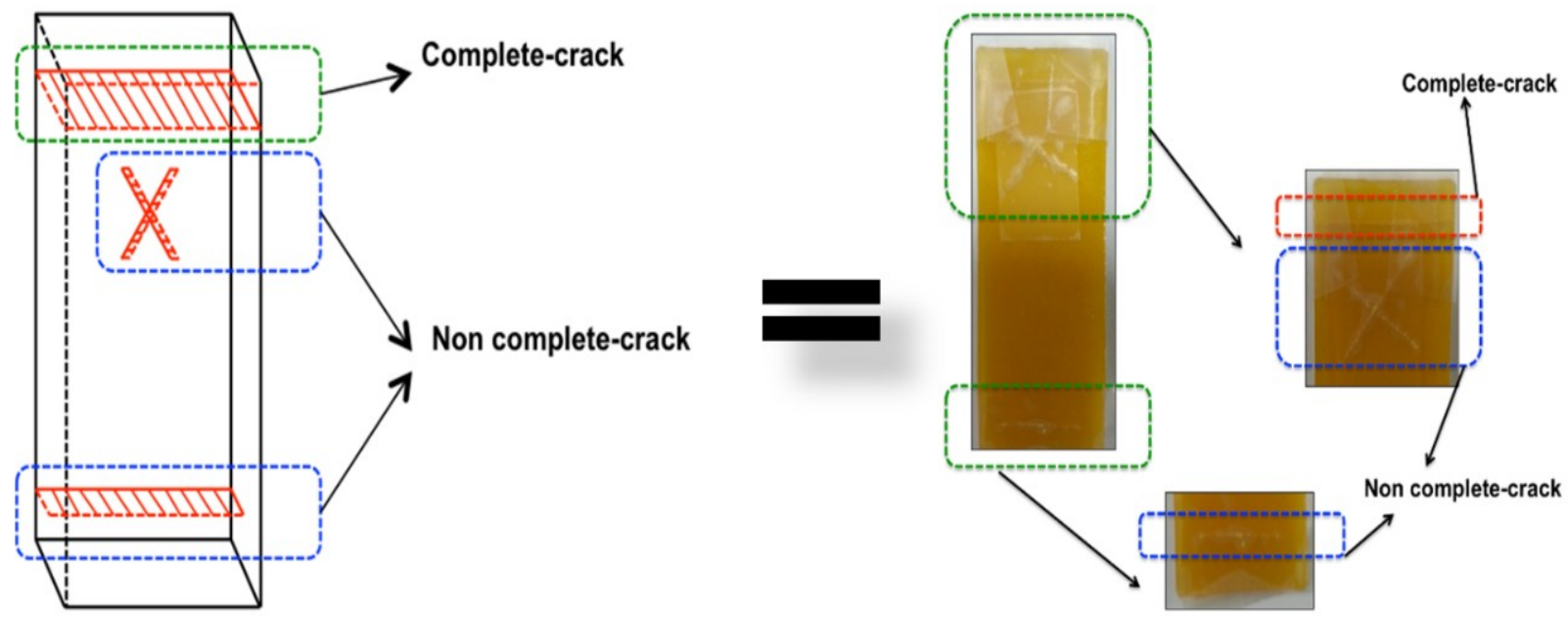

Figure 12: Schematic of complete-crack and non-complete-crack on PU/MCs-based SHMs.

Gragert et al. (15) conducted an investigation of two different healing agents (azide and alkyne compounds)-contained capsules on a highmolecular-weight poly(isobutylene) matrix, resulting that the specimens could be recovered after 5 days at $25^{\circ} \mathrm{C}(91 \%)$ or 3 days at $60{ }^{\circ} \mathrm{C}$ $(107 \%)$ through the shear-induced click crosslinking. Akhan et al. (16) preformed a survey of one healing agent (azide compound)-contained capsule on an alkyne-graphene oxide matrix with the use of CuAAC click reaction, leading to improving the self-healing efficiency through an incorporation of the low molecular weight selfhealing agent within the microcapsule. Besides, Saikia et al. (18) designed an azide-alkyne cycloaddition-based SHMs through azide-multiwall carbon nanotubes with poly(t-butyl acrylate) and alkyne compound-contained capsule embedded in an epoxy matrix, manifesting that this SHM recovered as much as $65 \%$ of its original fracture toughness. Herein, the self-healing ability of the as-prepared PU/MCs-based SHMs on the basic of only one type of healing agent (alkyne compound)contained capsule is surveyed through various weight ratios of MCs and cracks. PU/MCs-based SHMs have been prepared by adding the PUF/BPS MCs into PU matrix with four different weight ratios of the MCs (i.e.: 5, 10, 25, and 40\%). After the curing process of PU/MCs-based SHMs, these samples are cut following the complete-crack and non-complete-crack, which are then put into oven at $60{ }^{\circ} \mathrm{C}$ as described in Figures 12 and 13. The resulting that the prepared SHMs have not selfhealed at various cracked regions after 7 days, it means that the BPS amount in the MCs is not enough to conduct reacting with the azide groups of PU matrix at the cracked regions. However, these cannot explain that the calculated BPS amount in the MCs is quantitatively correct. Thus, to further investigate that, BPS is injected into crack regions of above PU/MCs-based SHMs to be manually delivered to the cracked regions using a syringe, which are then put into an oven $\left(60^{\circ} \mathrm{C}\right)$ for 7 days (Figure 13). For the SHMs containing $5 \%$ and $10 \%$ of MCs, "azide-alkyne" click has occurred completely at various cracked regions, except for the complete-cracked region of the SHMs containing $10 \%$ of MCs. The "azide-alkyne" click has not effectively occurred at each cracked region of the SHMs containing $25 \%$ and $40 \%$ of MCs, although an amount of BPS has been injected manually into the cracked regions from a syringe. It means that the amount of the MCs actually occupies more than that of the azide groups of PU matrix at the cracked regions. Although the BPS liquid on the surface of each sample disappeared after 7 days as shown in Figures 13 ( 3 and 4), they are injected manually into the cracked regions, indicating that injected BPS has diffused into samples to react with the azide groups of $\mathrm{PU}$ matrix. However, the diffusion regions in the phenomena have not yet been clearly explained here. 
1. Cut $\rightarrow$ put oven

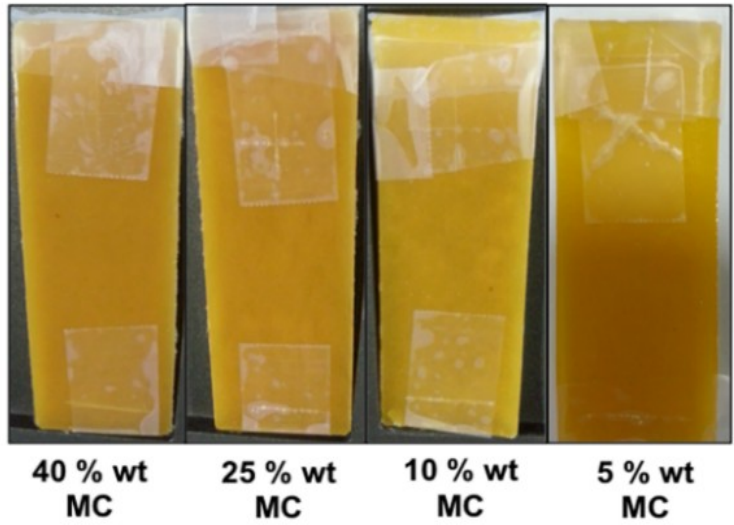

3. Inject BPS $\rightarrow$ put oven

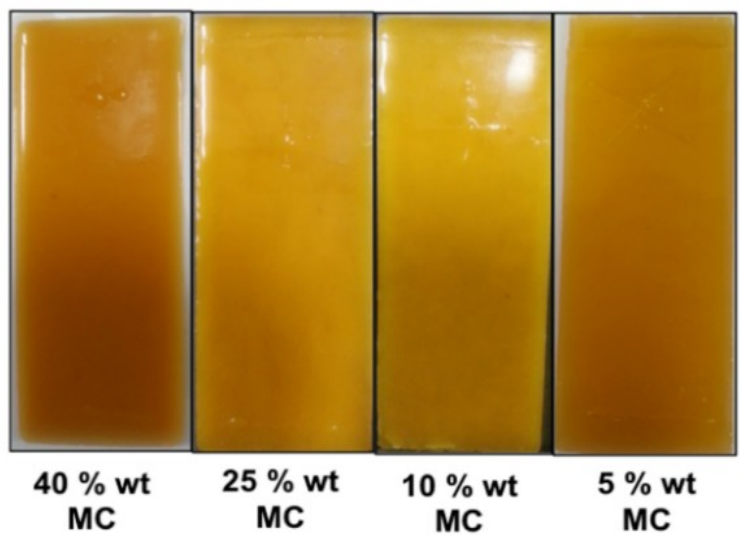

2. After 7 days

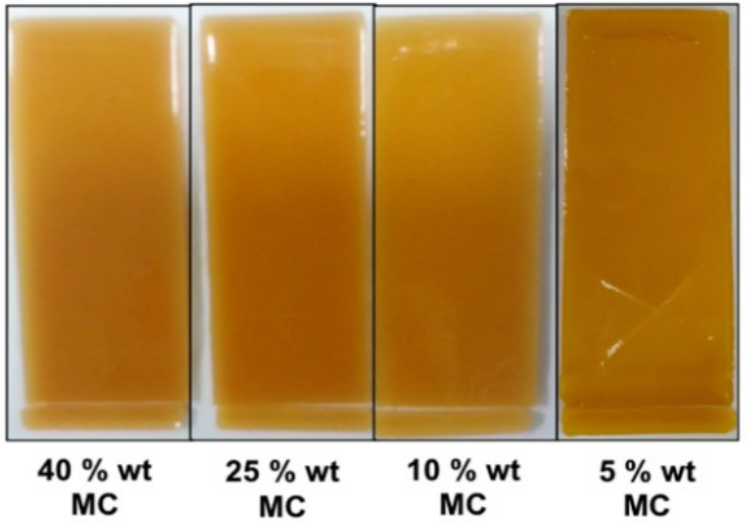

4. After 7 days

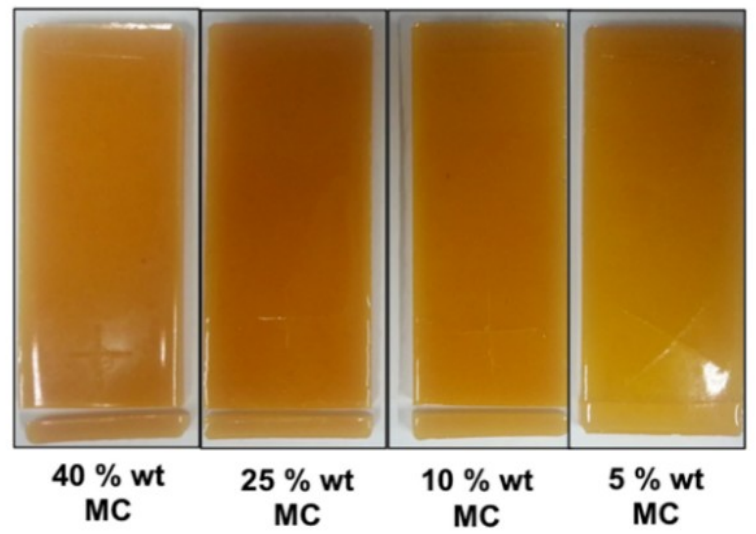

Figure 13: Influence of weight ratios of the MCs and injected BPS into PU/BPS-based SHMs.

In order to further explain the results mentioned above, an SHM containing MCs has been randomly distributed, as shown in Figure 14. It is assumed that a planar crack has occurred in this material system. All MCs then are intersected by the plane, and which will be broken to release core material. Besides, the number of broken MCs ( $n$ ) is calculated by Equation $9, \mathrm{~N}$ is seen as the total number of MCs in the sample, and $P$ is the probability of a broken MC. It means that the MCs are evenly distributed in the sample; the probability should be based on Equation 10; $\rho_{\mathrm{s}}, \mathrm{A}$, $\mathrm{d}_{\mathrm{c}}$, and $\mathrm{M}_{\mathrm{s}}$ are the density of the sample, the crack area, the diameter of the MCs, and the total mass of the sample, respectively. Besides, the total number of MCs in the PU/MCs-based SHMs can be calculated on the MCs weight fraction from Equation $11 ; \Phi$ and $\mathrm{m}_{\mathrm{c}}$ are the mass fraction and the mass of MCs, respectively. The amount of delivered BPS $(\mathrm{m})$ from the cracked area is calculated by Equation $12, \mathrm{~m}_{\mathrm{h}}$ is the total mass of BPS delivered, assuming all MCs intersected by the cracked region are broken. From Equations $9-12$, the available, total mass of BPS for delivery per unit crack area is calculated by Equation 13 . The above-mentioned total mass of BPS is proportional to both the weight fraction and the diameter of MCs (Table 1), as well as the self-healing ability can be controlled by both available BPS amount at the cracked region and achieved self-healing status.

$$
\begin{gathered}
\mathrm{n}=\mathrm{P} \cdot \mathrm{N} \\
\mathrm{P}=\frac{\rho_{\mathrm{s}} \cdot \mathrm{A} \cdot \mathrm{d}_{\mathrm{c}}}{\mathrm{M}_{\mathrm{s}}} \\
\mathrm{N}=\frac{\phi \cdot \mathrm{M}_{\mathrm{s}}}{\mathrm{m}_{\mathrm{c}}} \\
\mathrm{m}=\frac{\mathrm{m}_{\mathrm{h}}}{\mathrm{A}}=\frac{\mathrm{n} \cdot \mathrm{m}_{\mathrm{c}}}{\mathrm{A}} \\
\mathrm{m}=\rho_{\mathrm{s}} \cdot \phi \cdot \mathrm{d}_{\mathrm{c}}
\end{gathered}
$$

Furthermore, based on the visually observed results of the above samples (Figure 13), the samples have been designed with different cracks and MCs weight fractions to investigate the selfhealing ability. These results manifest that the observed healing performance is a combination of MCs' weight fraction and diameter in this material 
system. Overall, it is supposed that the selfhealing ability can depend on the amount of available BPS - healing agent, which can be supported from Equation 13. As a result, the BPS amount delivered autonomically from MCs is not enough to reach effectively the self-healing ability (Table 1). Here, the best healing capacity has been achieved for the SHMs containing $5 \%$ and $10 \%$ of MCs. Moreover, the MC's weight fraction and diameter relationship also affect the amount of core agent in the MCs distributed at the cracked region. According to some references, the PUF capsules with rougher surfaces and larger diameters are beneficial to appreciate the selfhealing efficiency of polymeric composites $(1,31)$. At the same time, the appreciated self-healing ability can be achieved by delivering much the healing agent into the cracked regions; according to theory, which suitable weight fractions of MCs can accomplish. However, for an actual self- healing efficiency, it can much depend on the necessary properties of the final product (i.e., its bonding strength with polymeric matrix, density, thickness, etc.).

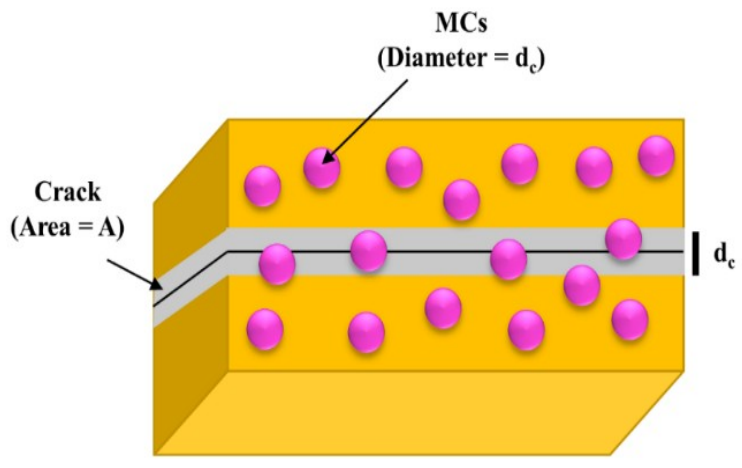

Figure 14: Schematic of PUF/BPS MCs in PU matrix.

Table 1: The amount of delivered BPS normalized by crack area.

\begin{tabular}{ccccc}
\hline Samples & $\begin{array}{c}\mathbf{d c} \\
(\boldsymbol{\mu m})\end{array}$ & $\begin{array}{c}\rho_{\mathbf{s}} \\
\left(\mathbf{g} / \mathbf{c m}^{\mathbf{3}}\right)\end{array}$ & $\begin{array}{c}\mathbf{\Phi} \\
(\%)\end{array}$ & $\begin{array}{c}\mathbf{m} \\
\left(\mathbf{g} / \mathbf{c m}^{\mathbf{2}}\right)^{*} \mathbf{1 0}^{\mathbf{4}}\end{array}$ \\
\hline $\mathbf{5} \mathbf{w t} \% \mathbf{M C s}$ & $63-125$ & 1.306 & 5 & $4.11-8.16$ \\
$\mathbf{1 0} \mathbf{w t} \%$ MCs & $63-125$ & 1.306 & 10 & $8.23-16.33$ \\
$\mathbf{2 5} \mathbf{w t} \%$ MCs & $63-125$ & 1.306 & 25 & $20.57-40.81$ \\
$\mathbf{4 0} \mathbf{w t} \% \mathbf{M C s}$ & $63-125$ & 1.306 & 40 & $32.91-65.30$ \\
\hline
\end{tabular}

\section{CONCLUSIONS}

In summary, the PUF shell has been prepared successfully by the in-situ polymerization. The PUF particles are precipitated through the fine powder formation and bonded to the surface of MCs. Concomitantly, the as-prepared MCs consist of both PUF - shell material and BPS - core agent, which are prepared successfully with up to $82.0 \%$ yield achieved based on the in-situ polymerization process of PUF shell. Additionally, the MCs have better thermal stability up to $257^{\circ} \mathrm{C}$ with the rough outer surface. The MCs have successfully encapsulated $75.0 \%$ of BPS with a size range of 63 - $125 \mu \mathrm{m}$ and the PUF shell thickness range of $5.72-11.35 \mu \mathrm{m}$; moreover, the stability of MCs is well maintained within 50 days at room temperature based on the solvent extraction method. In addition, the as-prepared PUF/BPS MCs have been employed to fabricate PU/MCs-based SHMs containing various weight ratios of the MCs, suggesting that the BPS amount is delivered autonomically through using $\mathrm{MCs}$ is too low to reach the self-healing ability effectively. Besides, the best healing performance has been achieved for the SHMs containing $5 \%$ and $10 \%$ of MCs when an amount of BPS has been injected manually into the cracked regions, indicating that the healing ability could be investigated. However, its bonding strength with polymeric matrix, thickness, density, etc., also involves self-healing efficiency. These can open an approach for the fabrication of capsule-based SHMs, and the characterization and reaction rate of the capsule-based SHMs can also be investigated in the next work.

\section{REFERENCES}

1. Brown EN, Kessler MR, Sottos NR, White SR. In situ poly(urea-formaldehyde) microencapsulation of dicyclopentadiene. Journal of

Microencapsulation. 2003;20(6):719-30. DOI: https://doi.org/10.3109/02652040309178083.

2. Yuan L, Liang G, Xie J, Li L, Guo J. Preparation and characterization of poly(urea-formaldehyde) 
microcapsules filled with epoxy resins. Polymer. 2006;47(15):5338-49. DOI:

https://doi.org/10.1016/j.polymer.2006.05.051.

3. Suryanarayana C, Rao KC, Kumar D.

Preparation and characterization of microcapsules containing linseed oil and its use in self-healing coatings. Progress in Organic Coatings.

2008;63(1):72-8. DOI:

https://doi.org/10.1016/j.porgcoat.2008.04.008.

4. Cosco S, Ambrogi V, Musto P, Carfagna C. Properties of poly(urea-formaldheyde) microcapsules containing an epoxy resin. Journal of Applied Polymer Science. 2007;105(3):140011. DOI: https://doi.org/10.1002/app.26263.

5. Keller MW, Sottos NR. Mechanical Properties of Microcapsules Used in a Self-Healing Polymer. Experimental Mechanics. 2006;46(6):725-33. DOI: https://doi.org/10.1007/s11340-006-9659-3.

6. Ghorbanzadeh Ahangari M, Fereidoon A, Jahanshahi M, Sharifi N. Effect of nanoparticles on the micromechanical and surface properties of poly(urea-formaldehyde) composite microcapsules. Composites Part B: Engineering. 2014;56:450-5. DOI:

https://doi.org/10.1016/j.compositesb.2013.08.07 1 .

7. Acik G, Karabulut HRF, Altinkok C, Karatavuk AO. Synthesis and characterization of biodegradable polyurethanes made from cholic acid and I-lysine diisocyanate ethyl ester. Polymer Degradation and Stability. 2019;165:43-8. DOI: https://doi.org/10.1016/j.polymdegradstab.2019.0 $\underline{4.015}$.

8. Caraculacu AA, Coseri S. Isocyanates in polyaddition processes. Structure and reaction mechanisms. Progress in Polymer Science. 2001;26(5):799-851. DOI:

https://doi.org/10.1016/S0079-6700(00)00033-2.

9. Acik B, Acik G, Erdemi H. Synthesis and characterization of bile acid, poly ( $\varepsilon$-caprolactone) and L-lysine diisocyanate ethyl ester based polyurethanes and investigation of their biodegradability properties. European Polymer Journal. 2021;146:110247. DOI: https://doi.org/10.1016/j.eurpolymj.2020.110247.

10. Binder WH, Sachsenhofer R. 'Click' Chemistry in Polymer and Material Science: An Update: 'Click' Chemistry in Polymer and Material Science: An Update. Macromolecular Rapid Communications. 2008;29(12-13):952-81. DOI:

https://doi.org/10.1002/marc.200800089.
11. Díaz DD, Punna $S$, Holzer P, McPherson AK, Sharpless KB, Fokin VV, et al. Click chemistry in materials synthesis. 1. Adhesive polymers from copper-catalyzed azide-alkyne cycloaddition. Journal of Polymer Science Part A: Polymer Chemistry. 2004;42(17):4392-403. DOI: https://doi.org/10.1002/pola.20330.

12. Rostovtsev VV, Green LG, Fokin VV, Sharpless KB. A stepwise huisgen cycloaddition process: copper(I)-catalyzed regioselective "ligation" of azides and terminal alkynes. Angewandte Chemie International Edition. 2002;41(14):2596-9. DOI: https://doi.org/10.1002/15213773(20020715)41:14<2596::AIDANIE2596>3.0.CO;2-4.

13. Vo TS, Vo TTBC. Preparation and Characterization of Bis-Propargyl-Succinate, and its Application in Preliminary Healing Ability of Crosslinked Polyurethane using "Azide-Alkyne" Click. Journal of Engineering Science and Technology Review. 2020;13(4):110-6. DOI: https://doi.org/10.25103/jestr.134.10.

14. Vo TS, Vo TTBC, Tien TT, Sinh NT. Enhancement of mechanical property of modified polyurethane with bis-butyl succinate. Journal of the Turkish Chemical Society Section A: Chemistry. 2021;8(2):519-26. DOI:

https://doi.org/10.18596/jotcsa.878515.

15. Gragert M, Schunack M, Binder WH.

Azide/Alkyne-"Click"-Reactions of Encapsulated Reagents: Toward Self-Healing Materials. Macromolecular Rapid Communications. 2011;32(5):419-25. DOI: https://doi.org/10.1002/marc.201000687.

16. Akhan S, Oktay B, Özdemir OK, Madakbaş S, Kayaman Apohan N. Polyurethane graphene nanocomposites with self-healing properties by azide-alkyne click reaction. Materials Chemistry and Physics. 2020;254:123315. DOI: https://doi.org/10.1016/j.matchemphys.2020.123 $\underline{315}$.

17. Döhler D, Michael P, Binder WH. Autocatalysis in the Room Temperature Copper(I)-Catalyzed Alkyne-Azide "Click" Cycloaddition of Multivalent Poly(acrylate)s and Poly(isobutylene)s. Macromolecules. 2012;45(8):3335-45. DOI: https://doi.org/10.1021/ma300405v.

18. Saikia BJ, Dolui SK. Preparation and characterization of an azide-alkyne cycloaddition based self-healing system via a semiencapsulation method. RSC Advances. 2015;5(112):92480-9. DOI: https://doi.org/10.1039/C5RA17666B. 
19. Tornøe CW, Christensen C, Meldal M. Peptidotriazoles on solid phase: $[1,2,3]$-triazoles by regiospecific copper(i)-catalyzed 1,3-dipolar cycloadditions of terminal alkynes to azides. The Journal of Organic Chemistry. 2002;67(9):305764. DOI: https://doi.org/10.1021/jo011148j.

20. Gorman IE, Willer RL, Kemp LK, Storey RF. Development of a triazole-cure resin system for composites: Evaluation of alkyne curatives. Polymer. 2012;53(13):2548-58. DOI: https://doi.org/10.1016/j.polymer.2012.04.002.

21. Osemeahon SA, Barminas JT. Development of amino resin for emulsion paint formulation: reactive blending of methylol urea with soybean oil. African Journal of Biotechnology. 2007;6(6):803-9. DOI: https://doi.org/10.4314/ajb.v6i6.56907.

22. Osemeahon SA, Barminas JT. Study of some physical properties of urea formaldehyde and urea proparaldehyde copolymer composite for emulsion paint formulation. International Journal of Physical Sciences. 2007; 2: 169-177. DOI: https://doi.org/10.5897/IJPS.9000533.

23. Liu Q, Zhang J, Liu W, Guo F, Pei J, Zhu C, et al. Preparation and characterization of self-healing microcapsules embedding waterborne epoxy resin and curing agent for asphalt materials.

Construction and Building Materials. 2018;183:384-94. DOI: https://doi.org/10.1016/j.conbuildmat.2018.06.18 $\underline{5}$.

24. Liao LP, Zhang W, Zhao Y, Li WJ. Preparation and Characterization of Microcapsules for Selfhealing Materials. Chemical Research in Chinese Universities. 2010; 26: 496-500.

25. Cai X, Fu D, Qu A. Effects of processing conditions on the properties of epoxy resin microcapsule. J Wuhan Univ Technol-Mat Sci Edit. 2015;30(4):689-94. DOI: https://doi.org/10.1007/s11595-015-1213-7.

26. Arshad MA, Maaroufi A, Benavente R, Pinto G. Kinetics of the thermal degradation mechanisms in urea-formaldehyde cellulose composites filled with zinc particles. Journal of Materials Science:

Materials in Electronics. 2017;28(16):11832-45.

DOI: https://doi.org/10.1007/s10854-017-6991-6.

27. Arshad MA, Maaroufi A, Benavente R, Pinto G. Thermal degradation of urea-formaldehyde cellulose composites filled with aluminum particles: Kinetic approach to mechanisms. Journal of Applied Polymer Science. 2017;134(19). DOI: https://doi.org/10.1002/app.44826.
28. Arshad MA, Maaroufi A, Pinto G, El-Barkany S, Elidrissi A. Morphology, thermal stability and thermal degradation kinetics of cellulose-modified urea-formaldehyde resin. Bulletin of Materials Science. 2016;39(6):1609-18. DOI: https://doi.org/10.1007/s12034-016-1304-x.

29. Jadhao MM, Paliwal LJ, Bhave NS. Resin II: Thermal degradation studies of terpolymer resins derived from 2,2'-dihydroxybiphenyl, urea, and formaldehyde. Journal of Applied Polymer Science. 2006;101(1):227-32. DOI:

https://doi.org/10.1002/app.23224.

30. Camino G, Operti L, Trossarelli L. Mechanism of thermal degradation of urea-formaldehyde polycondensates. Polymer Degradation and Stability. 1983;5(3):161-72. DOI: https://doi.org/10.1016/0141-3910(83)90007-1.

31. Brown EN, White SR, Sottos NR. Retardation and repair of fatigue cracks in a microcapsule toughened epoxy composite-Part II: In situ selfhealing. Composites Science and Technology. 2005;65(15):2474-80. DOI: https://doi.org/10.1016/j.compscitech.2005.04.05 3. 
Vo TS et al. JOTCSA. 2021; 8(3): 787-802.

RESEARCH ARTICLE 